\title{
Effect of Argan Oil-Hydrogen Peroxide Mixture on Mycobacterium tuberculosis- In Vitro
}

Anwar K. AL-Saffar* and Hussein O. M. Al-Dahmoshi

Babylon University-College of Science, Biology Department, Hilla-Iraq

\begin{abstract}
Objective: Tuberculosis (TB) is the threatful infectious disease that dwell about one third of worlds. Among Middle East, Iraq occupy the fifth order country endemic with TB.

Methodology: Six mixtures of Argan oil: $1.5 \% \mathrm{H}_{2} \mathrm{O}_{2}$ were prepared at different ratio: $1=0.75: 9.25,2=1: 9$, $3=1.5: 8.5,4=2: 8,5=2.5: 7.5,6=3: 7$ and mixed with Lowenstein-Jensen (L-J) medium. Seventeen Mycobacterium tuberculosis isolates got from the consultants clinic of respiratory and thoracic diseases in Hilla city-Iraq. All isolates cultured on LJ medium containing the mixture of Argan oil: $1.5 \% \mathrm{H}_{2} \mathrm{O}_{2}$ in different ratio and control tube (LJ without mixture) also used. The growth monitored per a day and recorded at different interval and the inhibition (no growth) were recorded.
\end{abstract}

Results: The effect of Argan oil: $1.5 \% \mathrm{H}_{2} \mathrm{O}_{2}$ mixture on the Mycobacterium tuberculosis were investigated over three incubation intervals (14th -20 th, 21st -28 th and after 29th day). The results revealed the high Argan concentration mixture 2.5:7.5 and 3:7 give excellent inhibitory effect on Mycobacterium tuberculosis during full periods of incubation with inhibition percentage (64.71\%-82.35\%).

Conclusion: The current study aims to investigate the effects of argan oil on Mycobacterium tuberculosis and conclude the anti-mycobacterial activity of argan oil as a safe medication for prophylaxis and treatment of TB.

Keywords: Tuberculosis; Argan oil; MDR; XDR; Hydrogen peroxide

\section{Introduction}

One third of the world's population infected with Mycobacterium tuberculosis. It is the principal causative agent of the widespread disease, tuberculosis (TB), among human's beings. It comes second to HIV as a cause of fatality worldwide [1]. Globally, in 2011 World Health Organization (WHO) reported that the incidence rates of $\mathrm{TB}$ about 8.7 million case, of which 1.4 million not healed and died and also document that, annually 3 million person die due to TB [2,3]. Iraq occupy the fifth order among middle east countries infected with $\mathrm{TB}$ and about 3 thousands die due TB [3,4].

WHO and Ministry of Health of Iraq $(\mathrm{MOH})$ record that the incidence rate of TB decreased after during the period from 20112014 , the incidence rate is 45 case for 100,000 people (from 2005-2010 the is incidence rate 64 case for 100,000 people) [5,6]. Malnutrition person and those with low socio-economic status are targeted by TB and the main strategies to compact this devil can be achieved via good nutrition and high level of personal hygiene [7]. Tuberculosis still the major public health problem and emergence of multi-drug resistance TB (MDR-TB) and extensive drug resistance TB (XDR-TB) among $M$. tuberculosis(resistance to first and second line drugs respectively) push the scientist to investigate the effects of many oils and plant extract as alternative medications [8]. In 2013 approximately 5\% of patients infected with TB develop MDR-TB and about $9 \%$ of that MDR-TB has XDR-TB [9].

Morocco Argan oil is rich herbal and medical oil with beneficial compounds. It contain fatty acids (like myristic, palmitic, palmitoleic, heptadecanoic, stearic, oleic, linolic, linolenic, arachidic and gadoleic acids), sterols (includes schottenol, spinasterol, avenasterol and campesterol), tocopherols (alpha, beta, gamma and delta tocopherols) and triterpene. It also contains carotenes, phenols and squalene [10]. The benefit of argan oil in cosmetics and physiological disorders treatments were extensively studied while little information about antibacterial activity of argan oil gathered [11]. The antibacterial activity of argan oil was firstly studied against two perilous bacteria, Methicillin-resistant Staphylococcus aureus (MRSA) and Pseudomonas aeruginosa isolated from wounds infection $[12,13]$. The current study aims to investigate the effects of argan oil on M. tuberculosis.

\section{Materials and Methods}

\section{Mixture preparation}

Six mixtures of Argan oil: $1.5 \% \mathrm{H}_{2} \mathrm{O}_{2}$ was prepared at different ratio as follow:

$1=0.75: 9.25,2=1: 9,3=1.5: 8.5,4=2: 8,5=2.5: 7.5,6=3: 7$ and mixed with Lowenstein-Jensen (L-J) medium (Himedia/India).

\section{Bacterial isolates}

Seventeen Mycobacterium tuberculosis isolates got from the consultants clinic of respiratory and thoracic diseases in Hilla city-Iraq. All isolates cultured on LJ medium containing the mixture of Argan oil: $1.5 \% \mathrm{H}_{2} \mathrm{O}_{2}$ in different ratio and control tube (LJ without mixture) also used. The growth monitored per a day and recorded at different interval and the inhibition (no growth) were recorded.

*Corresponding author: Anwar Kadhim Hussein AL-Saffar, Babylon University-College of Science, Biology Department, Babylon-Hilla City, Iraq, Tel: 009647803879430; E-mail: anwaralsafar78@gmail.com

Received May 01, 2015; Accepted June 28, 2015; Published June 30, 2015

Citation: AL-Saffar AK, Al-Dahmoshi HOM (2015) Effect of Argan Oil-Hydrogen Peroxide Mixture on Mycobacterium tuberculosis-In Vitro. J Med Microb Diagn S3: 008. doi:10.4172/2161-0703.S3-008

Copyright: (c) 2015 AL-Saffar AK, et al. This is an open-access article distributed under the terms of the Creative Commons Attribution License, which permits unrestricted use, distribution, and reproduction in any medium, provided the original author and source are credited. 


\section{Results}

The results of growth were recorded among three incubation intervals $\left(14^{\text {th }}-20^{\text {th }}, 21^{\text {st }}-28^{\text {th }}\right.$ and after $29^{\text {th }}$ day). the results revealed that there is no well noted differences of inhibition percentage among mixture 0.75:9.25 and 1:9 during all incubation period $(58.82 \%$ for both mixture at first period, $47.06 \%$ and $41.18 \%$ for both mixture at second period, $17.65 \%$ and $29.41 \%$ for both mixture at third period as shown in Figure 1-3.

The results for rest mixtures over incubation periods give approximately same similarity of results with different percentage. The result of inhibition for mixture $1.5: 8.5$ was $70.58 \%, 58.82 \%$ and $35.29 \%$ respectively for $1^{\text {st }}, 2^{\text {nd }}$ And $3^{\text {rd }}$ periods. The percentages of inhibition for mixture $2: 8$ were $64.70 \%, 58.82 \%$ and $35.29 \%$ for $1^{\text {st }}, 2^{\text {nd }}$ And $3^{\text {rd }}$ incubation periods respectively. The high Argan concentration mixture 2.5:7.5 and 3:7 give same results of inhibition in which $82.35 \%$ for both mixtures for $1^{\text {st }}\left(14^{\text {th }}-20^{\text {th }}\right.$ day) period, $70.59 \%$ for both mixtures for $2^{\text {nd }}$ $\left(21^{\text {th }}-28^{\text {th }}\right.$ day) period and $64.71 \%$ for both mixtures for $3^{\text {rd }}$ (after $29^{\text {th }}$ day) as shown in Figures 1-3.

The result revealed excellent effect of Argan oil as antiMycobacterial alternative medication for long period that provide safe, economic, easily to metabolize and patient-friend medication. Our data in accordance with other results performed on Methicillin Resistance Staphylococcus aureus (MRSA) and Pseudomonas aeruginosa and confirm their effects on these microbes $[12,13]$.

\section{Discussion}

The antbacterial activity attributed to phenol and tocopherol compounds in argan oil $[14,15]$. Also the activity can be accounted to another component of argan oil like squalene. Argan oil contains

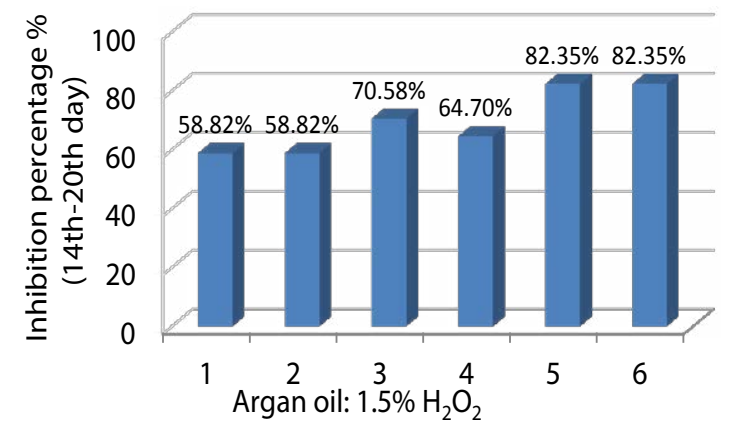

Figure 1: Inhibition Percentage for $1^{\text {st }}$ period of incubation $\left(14^{\text {th }}-20^{\text {th }}\right.$ Day).

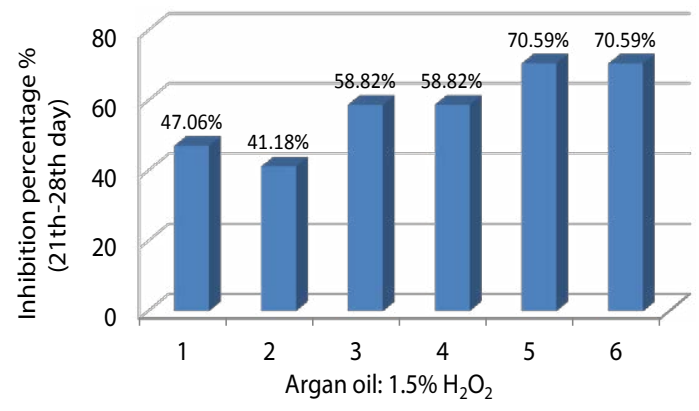

Figure 2: Inhibition Percentage for $2^{\text {nd }}$ period of incubation $\left(21^{\text {st }}-28^{\text {th }}\right.$ Day).

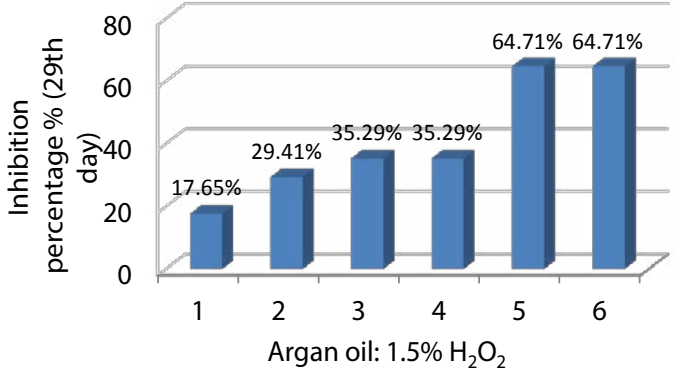

Figure 3: Inhibition Percentage for $3^{\text {rd }}$ period of incubation (After $29^{\text {th }}$ Day).

high content of squalene $(310 \mathrm{mg} / 100 \mathrm{~g})$ when compare with other medical oils. Squalene has both anti-bacterial and anti-fungal activities [16]. The anti-bacterial and anti-fungal compounds are spinasterol (41\%) and schottenol (47\%). The current study concludes the antimycobacterial activity of argan oil as a safe medication for prophylaxis and treatment of TB.

\section{References}

1. Rafiee S, Besharat S, Jabbari A, Golalipour F, Nasermoaadeli A, et al. (2009) Epidemiology of Tuberculosis in Northeast of Iran: A Population-Based Study. Iran J Med Sci 34: 193-197.

2. World Health Organization (WHO) (2006) Global Tuberculosis Control Report, 2006-Annex1 Profiles of high-burden countries.

3. World Health Organization (WHO) (2012) "Global tuberculosis control," WHO Report, WHO, Geneva, Switzerland.

4. Naher H, AL-Saffar A (2014) Novel Anti- tuberculosis Compound. IOSR Journal of Pharmacy and Biological Sciences 9: 1-5.

5. World Health Organization (WHO) (2011) Global tuberculosis control: WHO report 2011. WHO/HTM/TB/2011.16. Geneva, Switzerland.

6. Ministry of Health of Iraq, "New diagnosis of tuberculosis in Iraq," Tech Rep, Ministry of Health of Iraq, Baghdad, Iraq,2012.

7. Martin G, Lazarus A (2000) Epidemiology and diagnosis of tuberculosis. Recognition of at-risk patients is key to prompt detection. Postgrad Med 108 42-44, 47-50, 53-4.

8. Mustafa Ali R, Trovato A, Couvin D, Al-Thwani AN, Borroni E, et al. (2014) Molecular epidemiology and genotyping of Mycobacterium tuberculosis isolated in Baghdad. Biomed Res Int 2014: 580981.

9. World Health Organization (WHO) (2014) Multidrug-resistant tuberculosis (MDR-TB).

10. Charrouf Z, Guillaume D (2007) "Phenols and Polyphenols from Argania spinosa". Am. J. of FoodTechnology 2: 679-683.

11. Samane S, Christon R, Dombrowski L, Turcotte S, Charrouf Z, et al. (2009) Fish oil and argan oil intake differently modulate insulin resistance and glucose intolerance in a rat model of dietary-induced obesity. Metabolism 58: 909-919.

12. Naher HS, Al-Dahmoshi HO, Al-Khafaji NS, ALSaffar AK, AL-Saffar HK (2014) Anti-Pseudomonal Effect of Argan Oil on Pseudomonas aeruginosa Recovered from Burn Patients in Hilla City, Iraq. The Journal of Infectious Diseases. Photon 113: 270-276.

13. Naher HS, AL-Saffar AK, Al-Dahmoshi HO, Al-Khafaji NS, Naji NS, et al. (2014) Argan Oil as A Novel Anti-Methicillin Resistance Staphylococcus aureus (MRSA), Iraq. Global Journal of Medical research: Microbiology and Pathology 14: 15-18.

14. Ulusoy S, BoÅŸgelmez-Tinaz G, SeÃßilmiÅŸ-Canbay H (2009) Tocopherol, carotene, phenolic contents and antibacterial properties of rose essential oil, hydrosol and absolute. Curr Microbiol 59: 554-558.

15. Adetuyi FO, Ibrahim TA, Jude-Ojei, Ogundahunsi GA (2009) Total phenol tocopherol and antibacterial quality of honey Apis mellifera sold in Owo community, Ondo State, Nigeria. African Journal of Biotechnology 8: 1305-1309.

16. Kim SK, Karadeniz F (2012) Biological importance and applications of squalene and squalane. Adv Food Nutr Res 65: 223-233. 